\title{
Ernesto Odriozola Benavides (1862 - 1921) Semblanza
}

\section{Dr. LUIS ANGEL UGARTE}

En Lima, el 6 de Mayo de 1862, nació el Dr. Odriozola en el hogar patricio del Dr. Manuel Odriozola quien fuera uno de los Profesores que colaboraron con el Dr. Cayetano Heredia en la fundación de la Facultad de Medicina de San Fernando y de la que posteriormente fuera Decano, y de la Sra. Rosa Benavides de ilustre prosapia.

Inició sus estudios secundarios en Lima, y en 1878 ingresa a la Facultad de Medicina en donde obtiene el Bachillerato en 1883.

En Octudre de 1884, el Gobierno del General Iglesias, atropellando la autonomía universiraia, destituyo al Decano de la facultad de Medicina Dr. Manuel Odriozola provocando este hecho la renuncia masiva de los Profesores como expresión de protesta y en actitud de apoyo al Decanato. El Gobierno hizo caso omiso de esta actitud y nombró nuevo Decano y Profesores con lo que quedó consumado el atropello.

Con este motivo el entonces Bachiller Ernesto Odriozola viajo a Francia a continuar sus esiudios los que terminó en 1888 graduándose brillantemente como Dr. de Medicina en la Universidad de la Sorbona con una notable tesis «Le Coeur Senile». Ese mismo año, en junio, estuvo de regreso en la Patria.

La Facultad de San Fernando que desde que se pradujo el cambio de Gobierno en 1884 había repuesto en sus cargos al Decano Dr. Manuel Odrizola y a los profesores renunciantes, lo nombro Director de Anatomía, después de obtener la revalidación de su útulo de Médico Cirujano.

En 1889 optó el Grado de Doctor en Medicina y fue nombrado Jefe de Clínica de Mujeres. En 1891 pas6 a ser Profesor de Medicina operatoria, y Anatomía Topográfica. En 1904 obtuvo la Cátedra de Clínica Médica de Varones que conservó hasta su fallecimiento.

En 1889 fue incorporado a la Academia Nacional de Medicina que lo eligi6 como Secretario anual. Posteriormente en varias oportunidades fue elegido como Vicepresidente y Presidente desempeñándose en esos cargos con singular brillo.

En el mismo año de 1889 se incorporó a la «Sociedad Médica Unión Fernandinass la misma que en 1899 le tributó un magnifico homenaje público en el que le entregó una tarjeca de oro y lo eligio Miembro Honorario por su libro «La Maladie de Carrión». En ese acto el Dr. Enrique León García hizo la Historia de la Enfermedad de Carrín en la cual estableció, con mucho acierto, «el período Odriozola, período de luz y de cabal conocimiento de la enfermedad misteriosay.

En 1910 presidió las deliberaciones del Congreso Antialcohólico.

En 1913, como miembro del Comité Organizador del V Congreso Médico Latinoamericano, que tuvo sede en Lima, fue elegido Presidente de dicho Congreso.

En 1893 fue nombrado Médico de la Sala Santo Toribio del Hospital Dos de Mayo, a la que la Sociedad de Beneficiencia, después del fallecimiento del Dr. Odriozola, le puso el nombre de Sala Odriozola.

Fue miembro de la Sociedad Geográfica, del Consejo Universitario y del Consejo Nacional de Higiene. Desempeño el cargo de Vice-Rector de la Universidad y como tal le tocó desempeñar el Rectorado.
Todas las publicaciones médicas del país insertaron sus publicaciones que llegaron a la cifra de 250: «El Monitor Médico» (1888-1898); "LaGaceta de Hospitales» (1904-1911); «La Crónica Médica» (1898-1921); "Anales de la Facultad de Medicina» (19181920); «Revista de Psiquiatría Disciplinas Conexas», Revista de la Sociedad Médica Unión Fernardina y Centro de Estudiantes de Medicina.

Entre sus publicaciones son notables: «La Maladie de Carrión* que ha sido calificada como la de umejor sistematización expositiva, el resumen más acabado de la verruga peruana. Libro de enseñanza escrito con elegante sencillez, rico en información, pleno de documentación debidamente seleccionada». Su tesis «Le Coeur Senil», fue elogiada por el Profesor Letulle de la Universidad de París, de quien fue discipulo predilecto. Sus aLecciones Clínicas» que se han comparado con las de Trousseaux y :Dieulafoy le dieron mucho prestigio en Latino América y en España. Las Academias de Medicina de Río de Janeiro y de Caracas lo eligieron Miembro Correspondiente.

Murio súbitamente en su Oficina del Decanato de la Facultad de Medicina el 16 de Marzo de 1921.

Opiniones de sus colegas, sus discípulos y personas notables del país y extranjero. - «El más conspicuo médico del último cuarto de siglo, era el corifeo de las letras médicas peruanas... Cuando ocupó la Cátedra de Clínica médica era, sin disputa el médico más notable del Perú por sus cualidades intrínsecas, por su sólida cultura, por su práctica ya bastante dilatada; en su confianza había de admirar sus dotes de Maestro magnífico, comtemplar las fases de su análisis inquísitivo, para penetrar en la urdimbre práctica y conducidos por el hilo de la patografía más acabada, avizorar la terapéutica fructífera y oportuna...Fue el decano insustituible..Su gestión era siempre orientada por el derrotero más feliz y llevado a cabo con la más elevada de las miras» (Bambarén, Carlos - La Crónica Médica V. 38: 694, 98-103 Lima 1921) a... uno de los hombres de ciencia más ilustres y una de las personalidades más respetadas y notables (del Perú)... El vigor y solidez de su talento y de su ciencia le daban una amplitud, una penetración, una riqueza y un equilibrio admirables en las ideas y en su exposición y desarrollo en la Cátedra. De igual valor y merecimiento eran sus obras y publicaciones cientificas marcadas todas por el sello de su inteligencia superior y sus vastos conocimientos.

Dominaba por completo la ciencia médica, en la enseñanza y en el ejercicio profesional en la que todos buscan la autoridad indiscutida, la observación incomparable, el diagnóstico seguro del médico ilustre...La grandeza moral de su alma se elevaba a tanta altura como su inteligencia. Era una personalidad de rectitud, de nobleza y de bondad incomparables. No hubo circunstancia, accidente, amargura, ni prueba de la vida que quebrantara la integridad de su espíritu. Nunca pasión alguna oscurecio su mente ni perturbó sus sentimientos. Su vida fue inmaculada, jamás se apart6 del cumplimiento del deber. Su única aspiración era hacer el bien" (Prado, Javier, Rector de la Unjversidad, idem pág. 120-122). *Los altos méritos del Dr. Odriozola en el ejercicio de su hermoso 
apostolado educativo, la manera fecunda con que contribuyó a enriquecer el acervo científico americano, lo que le deben todas las generaciones médicas del país, todo ello está indeleblemente grabado en lo más íntimo de nuestro espíritu y han salido de nuestras fronteras continentales la egregia personalidad del maestro y la gloria rás pura que podemos exhibir con patriótico orgullo a los extraños... La vieja casa de Unánue ha perdido con él su figura más notable y nosotros los estudiantes el maestro más querido. No más nuestra alegría, cuando llenos de respeto le veíamos pasar, atrayéndonos siempre con su sonrisa paterna y cariñosa; no más la contemplación de su noble semblante cuando atentamente nos miraba, procurando penetrar en nustras almas con su visión inteligente para comprender el pensamiento que no acertaba a definir nuestro imperfecto lenguaje; no más las sabias lecciones de clínica médica, nuestro más preciado sustento intelectual y que le hicieron famosos en todo el continente... El Dr. Odriozola sentía inmenso cariño por los jóvenes, conocía doblemente sus deberes para ellos, y por la vocación natural e imperiosa de su espíritu los cumplía amorosamente, sin importarle para nada sacrificio ni dolor. Nosostros que le veíamos escuchar, lleno de bondad, nuestras inciativas, ser benévolo y atento para todas nuestras juveniles rebeldías, comprendemos hoy la inmensidad de nuestra pérdiđa». (Valega, Juan Francisco Presidente de la Federación de Estudiantes. Id. pág. 124-125).

*La vigorosa capacidad científica del Dr. Odriozola lleg6 a imponerse no solo en nuestro país sino en el exterior. Constituía una de nuestras legítimas glorias y el orgullo de la Patria. Su vida consagrada por entero a la ciencia y al ejercicio de noble apostolado del magisterio es un ejemplo para las jóvenes generaciones...

Maestro incomparable, su Cátedra de Clínica Médica fue manantial inagotable y siempre renovado de ensefranza fecunda. Clínico insuperable, dotado de incomparable poder intuitivo, maravilló a sus alumnos en sus admirables lecciones y así las generaciones que pasaban por su Cátedra salían de ella con la más honda gratitud por la enseñanza recibida y la más profunda admiración por talento excepcional.

Pero donde se dibuja en todo su relieve la personalidad del Dr. Odriozola, donde fulge en todo su esplendor la imagen del apóstol, es al frente de la Facultad de Medicina.

El movimiento estudiantil de 1919 nos proporciono la feliz oportunidad de apreciar en todo su valor la bondad infinita de su alma generosa, la máxima ponderación de su espíritu y el fervor, el santo amor que profesaba a la Escuela de San Fernando. A ella dedicaba todos sus desvelos, para ella fueron todos sus afectos... La juventud de San Fernando, aún en los más álgidos momentos del conflicto, fue recibida por el maestro con el mismo paternal afecto. Las puertas de su casa abiertas estuvieron siempre para nosotros y cuantas veces acudimos a ella encontramos al maestro dispuesto siempre a la cariñosa acogida, al consejo amistoso.

La gloria y el Justre de San Fernando constituían para él su más fervoroso ideal... y cuando terminó el movimiento renovador, comenz 6 con tesón y entusiasmo juvenil a laborar nuevamente por el progreso ascendente de la Escuela, su justiciera comprensión del espíritu sincero de la juventud, su cálido afecto por ella lo llevó a buscar su colaboración para la magna obra de renovación de la vieja casa de Unánue. He allí porque los estudiantes de medicina llegaron a sintetizar en la persona del Dr. Odriozola el tipo de Maestro ideal y porque fueron para él todos sus afectos, todas sus simpatías y toda su admiración; y ellos muy poco dispuestos a rendir homenajes, exteriorizaron hacia él su cariño sin restricciones; concediéndole la más alta distinción honorífica en el seno de la institución haciénóole su presidente honorario. $Y$ en el Primer Congreso Nacional de Estudiantes del Cuzco fue ungido como Maestro en el voto de aplauso y admiración entusiasta de la juventud universitaria de toda la República * (Guzmán Barrón, Eleazar, Presidente del Centro de Estudiantes de Medicina. Id. pág. 126)».

*Todos los que hemos asistido a las lecciones de Odriozola guardamos memoria imborrable de ellas: la dicción era galana, la crítica clfnica era severa y f́ácil; la gimnasia propedéutica era grata y a lección terminada el aplauso cálido y expontáneo. Las clases de Odriozola ienían el privilegio de reunimos a médicos y esudiantes, ya que para todos babía en aquellas lecciones provecho y agrado... en la candente arena de la práctica civil supo mantener una posición de brillo y de honorabilidad llevando a todas las juntas el contingente muy valioso de su práctica serena, de su preparación siempre renovada, de su crítica eficaz... Lo recuerdan con cariño los enfermos del hospital con lo que fue sabio, bueno y solícito.

Con idéntico cariño lo recuerdan los alumnos, que recibieron de él valiosas enseñanzas. Y le recuerdan con el mismo afecto sus numerosos enfermos, aquellos que de él recibieron los bienes de la salud y del consuelo. Sus compañeros de Facultad, muchos de ellos discípulos suyos, no ban de olvidarlo jamás». (Valdizán, Hermilio, Profesor de la facultad de Medicina, En «Artículos Necrológicos, Juicios Críticos, Discursos -- Imprenta Torres Aguirre 1927 - pág. 15-19).

«En Odriozola había toda la tradición clínica y didáctica de la Escuela Francesa... Odriozola ba concentrado en sus clínicas del Hospital la esencia del saber médico.. Hombre versado en la práctica diaria de los enfermos y con gran agilidad intelectual, no descuidaba ni el error diagnóstico para hacer de estos fracasdos clínicos una enseñanaza y un ejemplo». (El Siglo Médico -- Madrid).

«El Profesor Odriozola es el más conspicuo médico peruano del último cuarto de siglo» (Dr. Nascimento Guragel -- Boletín de la Academia de Medicina de Río Janeiro -- 8 de junio 1921).

*Autor de numerosos trabajos científicos supo demostrar en todos los cargos que lleg6 a ocupar tan relievantes condiciones que con toda justicia era considerado en aquella Patria hermana como el Maestro en quien se encarnaban las más excelsas virtudes, la más prestigiosa inteleceualidad, las más descollantes cualidades de observación y de experiencia, puestos durante toda su vida al servicio de la enser̃anza clínica y del ejecicio profesional». (Boletín del Consejo Nacional de Higiene, Uruguay Junio de 1921).

«Sabio hispano americano, verdadero exponente científico de nuestra raza, hombre consagrado a la investigación cientifica, excelente cultor de las letras y maestro pulcro... Con tanto gusto leíamos sus conferencias clínicas que mensualmente publicaba la Crónica Médica de Limaw. (Revista Médico Quirúrgica de Tegucigalpa). 